\title{
Transparency in conducting and reporting research: a survey of authors, reviewers, and editors across scholarly disciplines
}

\section{Mario Malički ( $\square$ mario.malicki@mefst.hr)}

Urban Vitality Centre of Expertise, Amsterdam University of Applied Sciences, Amsterdam, The

Netherlands https://orcid.org/0000-0003-0698-1930

\section{IJsbrand Jan Aalbersberg}

Elsevier, Amsterdam, The Netherlands https://orcid.org/0000-0002-0209-4480

\section{Lex Bouter}

Department of Philosophy, Faculty of Humanities, Vrije Universiteit, Amsterdam, The Netherlands and Amsterdam University Medical Centers, Department of Epidemiology and Data Science, Amsterdam, The Netherlands https://orcid.org/0000-0002-2659-5482

\section{Adrian Mulligan}

Elsevier, Oxford, UK

\section{Gerben ter Riet}

Urban Vitality Centre of Expertise, Amsterdam University of Applied Sciences, Amsterdam, The Netherlands and Amsterdam University Medical Centers, Department of Cardiology, Amsterdam, The Netherlands

\section{Research Article}

Keywords: survey, transparency, reporting, detrimental research practices, work climate

Posted Date: January 26th, 2022

DOI: https://doi.org/10.21203/rs.3.rs-1296644/v1

License: (c) (i) This work is licensed under a Creative Commons Attribution 4.0 International License. Read Full License 


\section{Abstract}

Calls have been made for improving transparency in conducting and reporting research, improving work climates, and preventing detrimental research practices. To assess attitudes and practices regarding these topics, we sent a survey to authors, reviewers, and editors. We received 3,659 (4.9\%) responses out of 74,749 delivered emails. We found no significant differences between authors', reviewers', and editors' attitudes towards transparency in conducting and reporting research, or towards their perceptions of work climates. Undeserved authorship was perceived by all groups as the most prevalent detrimental research practice, while fabrication, falsification, plagiarism, and not citing prior relevant research, were seen as more prevalent by editors than authors or reviewers. Overall, $20 \%$ of respondents admitted sacrificing the quality of their publications for quantity, and $14 \%$ reported that funders interfered in their study design or reporting. Our results indicate that greater involvement of all stakeholders is needed to align actual practices with current recommendations.

\section{Introduction}

Scholarly publishing has been steadily growing for the last two centuries with more than 3 million articles published per year. ${ }^{1}$ In recent times, there has been an increasing focus on the detection and prevention of misconduct and detrimental research practices, in enhancing research rigor and transparency, and in cultivating a research climate best suited to foster these goals. ${ }^{2-5}$ Specifically, calls have been made to increase the transparency in conducting and reporting research by registering projects and data analyses plans before data collection, using reporting guidelines when writing up studies, posting preprints, sharing (raw) data, reproducing or replicating studies, as well as rewarding, hiring or promoting researchers based on these practices. ${ }^{6-9}$ One such call was made in 2014, when the Transparency and Openness Promotion (TOP) Committee developed eight transparency standards related to: 1) citations, 2) data, 3) analytic methods (code), 4) research materials, 5) data and analysis reporting, 6) preregistration of studies, 7) preregistration of analysis plans, and 8) replication of research. ${ }^{10}$ Since then, more than 5,000 journals and 80 organizations became TOP signatories. ${ }^{11}$ However, to the best of our knowledge, attitudes related to all aspects of TOP guidelines have not been systematically assessed, and, yet, without agreement from all stakeholders regarding these guidelines, it is unlikely that scholarly practices will change.

It was therefore our goal to assess differences in attitudes and perceptions between authors, reviewers, and editors regarding the TOP guidelines, differences in perceptions of their work climates, and differences in their perceived prevalence of responsible and detrimental research practices.

\section{Methods}

We reported our study following the Strengthening the Reporting of Observational Studies in Epidemiology (STROBE) guidelines, ${ }^{12}$ as well as the Checklist for Reporting Results of Internet E-Surveys (CHERRIES). ${ }^{13}$ 


\section{Study design and participants}

Full methodological details of our study, including its registration and study protocol are available at our

project's data repository. ${ }^{14}$ In short, we sent a survey to 100,000 email addresses. The email addresses were from: 1) randomly selected corresponding authors of papers indexed in Scopus ( $n=99,708)$; or 2$)$ editors whose Instructions to Authors we analysed in our previous study $(\mathrm{n}=292){ }^{15}$

\section{Setting}

The survey was sent on 24 April 2018, had reminders on 9 and 24 May, and was closed on 12 June of that same year. The survey invitation and reminders, full survey questions and details of their development and testing are available on our project's data repository. ${ }^{14}$ Respondents could skip items and change the answers they gave until submitting their responses by clicking on the "close the survey" button.

\section{Variables and their measurement}

The survey was divided into 4 sections and the questions were presented in the same order to all participants:

1. attitudes towards transparency in conducting and reporting research (11 questions covering the TOP guidelines with 5-point Likert-type answers ranging from strongly agree to strongly disagree);

2. perceptions of work climate (13 questions with 5-point Likert-type answers ranging from strongly agree to strongly disagree);

3. perceived prevalence of responsible and detrimental research practices (14 questions with 5-point Likert-type answers ranging from very prevalent to never occurring);

4. sociodemographic and knowledge of statistics questions (10 questions with categorical answers).

All questions for the first three sections also included a Don't know/Not applicable option. Additionally, we had open-ended questions (free text format) that explored reasons for respondents' (dis)agreement with questions of first three sections, and a final survey question for general feedback on the survey. In order to maintain the focus on quantitative data and have a reasonable reporting length, analysis of openended answers is planned for another publication.

\section{Statistical methods and study bias}

We conducted all analyses in STATA v.13, with statistical code and outputs published on our project's data repository. ${ }^{14}$ The grouping of respondents to authors (A), reviewers (R) and editors (E) is explained in detail in the Appendix. The main outcomes (answers to questions in sections 1 to 3 listed above) are presented as absolute numbers and percentages (calculated on the basis of the number of respondents that answered a specific question). For readability, percentages are shown only for those who agreed or strongly agreed to statements, or that perceived prevalent or very prevalent practices. Data for all answer 
options are available on our project's data repository. ${ }^{14}$ Differences in sociodemographic characteristics and knowledge of statistics between authors, reviewers and editors were explored using the chi-squared test for categorical variables, and Kruskal-Wallis test for respondents' age. To explore possible associations between answers to questions of sections 1 to 3 and explanatory variables (sociodemographic characteristics and knowledge of statistics) we used ordinal regression analyses. We conducted regressions for all 38 questions individually. We also explored treating questions of each section as separate scales (with the scales consisting of 11,13 and 14 questions, respectively). We constructed 3 summary scores for those scales, which we then also explored in ordinal regression analyses. To adjust for multiple comparisons, we considered $p \leq 0.001$ as statistically significant (based on the Bonferroni correction method of dividing 0.05 by 50 , which was the number of conducted regressions rounded-up to the nearest decile). For readability, regression outputs are presented graphically in the Appendix, while details of analyses, odds ratios and their associated $95 \% \mathrm{Cl}$ are available on our project's data repository. ${ }^{14}$

\section{Respondents' inquiries and deviations from the protocol}

In the invite email, respondents were asked to contact us if they encountered any (technical) difficulties. Details of their questions and deviations from the study protocol are listed in the Appendix.

\section{Ethics approval}

An ethics waiver for the study has been obtained on 6 April 2018 from the Medical Ethics Review Committee of the Academic Medical Center, University of Amsterdam (reference number W18_112). The survey invitation (available on our project's data repository ${ }^{14}$ ) included information on the study purpose, investigators, estimated length to complete the survey, planned sharing of anonymised data, and publication of summary results. No incentives were offered for participation.

\section{Results}

Our overall response rate was $4.9 \%$ (3,659 out of 74,749 delivered emails) and included responses from 1,389 authors, 1,833 reviewers, and 434 editors. Respondents came from 126 countries, most commonly USA (16\%), India (8\%), Italy (7\%), and Brazil (5\%). Respondents' median age was 44 (IQR 35 to 55, range 23 to 90$)$. The majority worked for universities or colleges $(62 \%)$, and were male $(66 \%)$. While respondents came from all scholarly disciplines, most were from Physical (33\%) or Life Sciences (25\%). Similarly, while respondents came from all career stages, most had a publication record of 6 to 25 publications $(39 \%)$, or more than 50 publications $(25 \%)$. Finally, most respondents considered themselves to have either basic (44\%) or intermediate (45\%) knowledge of statistics. Full details on response rate calculation, assignment of respondents to authors, reviewers, and editors, their self-declared statistical knowledge, and sociodemographic characteristics are available in the Appendix. Summary results are presented below, while all answers, as well as percentages of respondents who chose "Don't know" or "Not applicable" options, are shown in the Appendix. 
Respondents' attitudes towards 11 statements on transparency in reporting and conducting research, which were based on TOP guidelines, are shown in Table 1. The lowest support, across all respondents, was for preregistering studies prior to conducting the research (21\%), and the highest for appropriately citing all data, analytic methods (program code) and materials used in the study (95\%). Regression analyses (Appendix Table A7) revealed no significant differences between authors, editors and reviewers and significant associations for 3 factors: 1) discipline - HealthSciences researchers had more positive attitudes towards transparency in reporting and conducting research than researchers of other disciplines; 2) number of publications - researchers with less than 6 publications had more positive attitudes than other researchers; 3 ) country - respondents from India had more positive attitudes than respondents from other countries (Table 2).

Table 1. Respondents' attitudes toward transparency in reporting and conducting research. In the numerical comparison differences between groups larger than $5 \%$ are in bold. In the graphical comparison highest percentage is darker.

\begin{tabular}{|c|c|c|c|c|c|}
\hline Statement - \%of respondents who (strongly) agreed ${ }^{*}$ & $\begin{array}{c}\text { Authors } \\
(\mathrm{n}=1,389)\end{array}$ & $\begin{array}{c}\text { Reviewers } \\
(\mathrm{n}=1,833)\end{array}$ & $\begin{array}{l}\text { Editors } \\
(n=434)\end{array}$ & $\begin{array}{l}\text { Graphical } \\
\text { comparison }\end{array}$ & $\begin{array}{c}\text { Total } \\
(\mathrm{n}=3,659)\end{array}$ \\
\hline $\begin{array}{l}\text { Authors must appropriately cite all data, analytic methods (program code) and } \\
\text { materials used in the study. }\end{array}$ & 93 & 96 & 95 & & 95 \\
\hline $\begin{array}{l}\text { Authors mustindicate whether the data, analytic methods (program code), and } \\
\text { research materials will be made available to any researcher for purposes of } \\
\text { reproducing the results or replicating the procedures. }\end{array}$ & 82 & 85 & 83 & & 83 \\
\hline $\begin{array}{l}\text { Authors must follow appropriate reporting guidelines (e.g. those from } \\
\text { www.equator-network org) for di sclosing key aspects of the research design } \\
\text { and data analysis. }\end{array}$ & 75 & 74 & 71 & & 74 \\
\hline $\begin{array}{l}\text { Journals must check and enforce appropriate reporting guidelines (e.g.those } \\
\text { from www.e quator-networkorg) for disclosing key aspects of the research } \\
\text { design and data analysis. }\end{array}$ & 71 & 67 & 62 & & 68 \\
\hline $\begin{array}{l}\text { Journals must encourage submission of replication studies, particularly of } \\
\text { research they publish. }\end{array}$ & 59 & 64 & 57 & & 61 \\
\hline $\begin{array}{l}\text { Authors must deposit all data, analytic methods (program code), and research } \\
\text { materials to a trusted reposi tory. All exceptions due to legal or ethical reasons } \\
\text { must be identified at arti cle submission. }\end{array}$ & 62 & 60 & 55 & & 60 \\
\hline $\begin{array}{l}\text { Journals must verify that the findings are repli cable using the deposited authors' } \\
\text { data and methods of analysis. }\end{array}$ & 58 & 46 & 38 & & 50 \\
\hline $\begin{array}{l}\text { Journals must employ a two-stage review process for replication studies - in } \\
\text { the first stage review the proposal for the replication study, and in the second } \\
\text { the full conducted study. }\end{array}$ & 42 & 33 & 30 & & 36 \\
\hline $\begin{array}{l}\text { Journals must check and indicate within the publication that a study had been } \\
\text { preregistered prior to the research being conducted. }\end{array}$ & 29 & 22 & 19 & ㅁㅁ밈 & 24 \\
\hline Authors must include the full data analysis plan in their study preregistration. & 26 & 21 & 21 & ㅁ뭄 & 23 \\
\hline Authors must preregister their study prior to conducting the research. & 26 & 19 & 18 & 므물 & 21 \\
\hline
\end{tabular}

*Questions are sorted by the total agreement percentage. Order of questions as they were asked in the survey is presented in the Appendix Slight variations exist for the number of respondents per question exact numbers are available on our proiect's data repository. 
Table 2. Examples of univariate comparisons that were confirmed in regression analyses to be significantly associated with attitudes towards transparency in reporting and conducting research, perceptions of work climate or perceived prevalence of responsible and detrimental research practices. In the graphical comparison highest percentage is darker. Slight variations exist for the number of respondents per question, exact numbers are available on our project's data repository.

\begin{tabular}{|c|c|c|}
\hline Statement / practice & Comparison groups & $\begin{array}{l}\text { Graphical } \\
\text { comparison }\end{array}$ \\
\hline
\end{tabular}

Examples of attitudes toward transparency in reporting and conducting research

\begin{tabular}{lccc}
\hline $\begin{array}{l}\text { Journals must verify that the findings are replicable using the deposited authors' } \\
\text { data and methods of analysis. }\end{array}$ & India & $\begin{array}{c}\text { Other } \\
\text { Countries }\end{array}$ \\
\hline
\end{tabular}

\begin{tabular}{lcc}
\hline Authors must preregister their study prior to conducting the research & $\begin{array}{c}\text { Health } \\
\text { Sciences }\end{array}$ & $\begin{array}{c}\text { Other } \\
\text { Sciences }\end{array}$ \\
\hline
\end{tabular}

Journals must employ a two-stage review process for replication studies - in the first stage review the proposal for the replication study, and in the second the full conducted study.

$\begin{array}{cc}\text { Authors with } & \text { Authors with } \\ <6 & \geq 6 \\ \text { publications } & \text { publications }\end{array}$

\begin{tabular}{|c|c|c|}
\hline \multicolumn{3}{|l|}{ Examples of perceptions of work climate } \\
\hline \multirow[t]{2}{*}{ Quality of peer review I received for my publications was generally high } & India & $\begin{array}{l}\text { Other } \\
\text { Countries }\end{array}$ \\
\hline & 79 & 65 \\
\hline \multirow[t]{2}{*}{ I am willing to publish studies with null or negative results. } & USA & $\begin{array}{l}\text { Other } \\
\text { Countries }\end{array}$ \\
\hline & 76 & 57 \\
\hline \multirow{3}{*}{$\begin{array}{l}\text { Due to the pressure to publish, I sacrifice the quality of my publications for } \\
\text { quantity. }\end{array}$} & Respondents & Respondents \\
\hline & $<35$ years old & $\geq 35$ years old \\
\hline & 28 & 18 \\
\hline
\end{tabular}

Examples of perceptions of prev alence of (detrimental) research practices

\begin{tabular}{lccc}
\hline Plagiarism & India & $\begin{array}{c}\text { Other } \\
\text { Countries }\end{array}$ \\
\hline & & 40 & 10 \\
Self-reporting of study limitations & Health & Other \\
& Sciences & Sciences \\
\hline & 55 & 28 \\
\hline
\end{tabular}

\section{Perceptions of work climate}

Respondents' perceptions on 13 statements about their own work climate are shown in Table 3. Most respondents stated that they share their research data with other researchers unless legal or ethical reasons prevent them from doing so (79\%), and that having access to others' data benefits (or would benefit) them (79\%). Two thirds (66\%) considered the quality of peer review they received to be generally high, as well as the quality of publications in their field (64\%). One fifth of respondents (20\%) stated that 
due to the pressure to publish they sacrifice the quality of their publications for quantity, and one seventh of respondents (14\%) stated that funders or sponsors interfered in their study design or study reporting. Regression analyses (Appendix Table A8) revealed no significant differences between authors, editors and reviewers and significant associations with perceptions of work climate with two factors: 1) country - respondents from India or USA had more positive perceptions of their work climate than respondents from other countries; 2) age -younger respondents perceived a worse work climate than older respondents (e.g., younger respondents perceived more pressure to sacrifice quality for quantity, and they more often stated that long peer review times had negatively impacted their careers, Table 2).

Table 3. Respondents' perceptions toward their work climate. In the numerical comparison differences betw een groups larger than $5 \%$ are in bold. In the graphical comparison highest percentage is darker.

\begin{tabular}{|c|c|c|c|c|c|}
\hline Statement - \%of respondents who (strongly) agreed* & $\begin{array}{c}\text { Authors } \\
(\mathrm{n}=1,389)\end{array}$ & $\begin{array}{c}\text { Reviewers } \\
(\mathrm{n}=1,833)\end{array}$ & $\begin{array}{l}\text { Editors } \\
(\mathrm{n}=434)\end{array}$ & $\begin{array}{l}\text { Graphical } \\
\text { comparison }\end{array}$ & $\begin{array}{c}\text { Total } \\
(\mathrm{n}=3,659)\end{array}$ \\
\hline $\begin{array}{l}\text { Unless legal or ethical reasons prevent it, I share my research data wi th other } \\
\text { researchers. }\end{array}$ & 75 & 81 & 81 & & 79 \\
\hline Having access to others' research data benefits/would benefit my own re search & 77 & 81 & 76 & & 79 \\
\hline It is difficult to publish studies wi th mull or negative re sults. & 69 & 76 & 70 & & 73 \\
\hline Quality of peer review I received for my publications was generally high. & 67 & 66 & 63 & & 66 \\
\hline Quality of publications in my field is generally high & 66 & 62 & 62 & & 64 \\
\hline I am willing to publish studies with null or negative results. & 54 & 61 & 62 & & 59 \\
\hline Authors recommending peer reviewers for their research is a good practice. & 57 & 51 & 55 & & 54 \\
\hline $\begin{array}{l}\text { Quality of mentoring of young scientists } \mathrm{PhD} \text { students in my field is generally } \\
\text { high }\end{array}$ & 49 & 55 & 57 & & 53 \\
\hline I find it easy to obtain ethics opinions (approvals) for my studies. & 45 & 46 & 49 & & 46 \\
\hline Time taken to have my work peer-reviewed has affected my career negatively. & 27 & 23 & 20 & $\square \square \square$ & 24 \\
\hline There is sufficient funding availability for research in my field. & 22 & 21 & 20 & 무 & 21 \\
\hline $\begin{array}{l}\text { Due to the pressure to publish, I sacrifice the quality of my publications for } \\
\text { quantity. }\end{array}$ & 24 & 19 & 15 & $\square \square$ & 20 \\
\hline Funders/sponsors interfere in my study design or study reporting. & 16 & 13 & 12 & 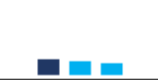 & 14 \\
\hline
\end{tabular}

\section{Perceived prevalence of responsible and detrimental research practices}


Respondents' perceived prevalence of responsible and detrimental research practices are shown in Table 4. Among detrimental practices, $38 \%$ of respondents perceived undeserved authorship, and $33 \%$, prior relevant research not being cited, as (very) prevalent in their field. Of responsible practices, $32 \%$ perceived self-reporting of limitations, $19 \%$ perceived sharing of raw data, and $6 \%$ publication of studies with null or negative results to be (very) prevalent. Regression analyses (Appendix Table A9) revealed editors perceiving fabrication, falsification, plagiarism, and omitting of references to be more prevalent than authors or reviewers. Additionally, editors also perceived undeclared conflicts of interest, and publication of studies with null or negative results to be more prevalent than reviewers (but not than authors, Appendix Table A9).

Regression analyses also revealed 3 other factors associated with the prevalence of research practices: 1) country - respondents from India or USA perceived detrimental research practices to be more prevalent than respondents from other countries; 2) discipline - Health Sciences respondents perceived responsible practices, i.e., use of reporting guidelines, open peer review, publication of studies with null or negative results, and reporting of study limitations as more prevalent than respondents from other disciplines, but they also perceived one detrimental practice - ghost writing - to be more prevalent than the respondents from other disciplines; 3 ) age -younger respondents perceived undeserved authorship, as well as prior relevant research not being cited, as more prevalent than older respondents (Table 2). 
Table 4. Respondents' perceptions of perceived prevalence of responsible and detrimental research practices. In the numerical comparison diffe rences be tween groups harger than $\mathbf{5} \%$ are in bold. In the graphical comparison highest percent age is darker.

\begin{tabular}{|c|c|c|c|c|c|}
\hline Practice - \%of respond ents who perceived it as (very) prevalent* & $\begin{array}{c}\text { Authors } \\
(\mathrm{n}=1,389)\end{array}$ & $\begin{array}{l}\text { Reviewers } \\
(\mathrm{n}=1,833)\end{array}$ & $\begin{array}{l}\text { Editors } \\
(\mathrm{n}=434)\end{array}$ & $\begin{array}{l}\text { Graphical } \\
\text { comparison }\end{array}$ & $\begin{array}{c}\text { Total } \\
(\mathrm{n}=3,659)\end{array}$ \\
\hline Undeserved authorship (i.e. guest or gift authorship) & 34 & 40 & 39 & & 38 \\
\hline References being omitted (i.e. prior r el evart r esearchnot being cited) & 27 & 35 & 46 & & 33 \\
\hline Self-reporting of study limitations & 28 & 33 & 35 & & 32 \\
\hline $\begin{array}{l}\text { Use of reporting gri delines for disclosing key aspects of the research design } \\
\text { and data analysis }\end{array}$ & 24 & 25 & 26 & & 25 \\
\hline Sharing of relevart raw data underlying a research study & 17 & 21 & 20 & $\square \square \square$ & 19 \\
\hline $\begin{array}{l}\text { Publishing of authors' versions (non-peer review ed versions) on pre-print } \\
\text { servers }\end{array}$ & 17 & 20 & 18 & $\square \square \square$ & 19 \\
\hline Ghost writing (i.e. author(s) not being acknowledged) & 15 & 13 & 15 & an & 14 \\
\hline Undeclar ed corflict(s) of inter est / competinginterest(s) & 17 & 12 & 14 & 믐ㅁ & 14 \\
\hline Plagarism & 16 & 10 & 15 & 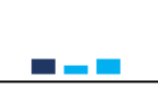 & 13 \\
\hline Open peer review (i.e. reviewers signing their review reports) & 16 & 11 & 12 & 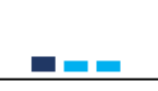 & 13 \\
\hline Fabrication or fal sification (ind. Image manipulation) & 12 & 9 & 12 & 므를 & 11 \\
\hline Publication of corrections (i.e. errata, corrigenda) & 11 & 10 & 13 & 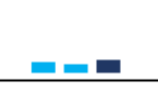 & 11 \\
\hline Publication of studies with null or neggtive results & 8 & 5 & 5 & -- & 6 \\
\hline Publication of retr actions (i.e. study withdrawal) & 6 & 4 & 4 & --- & 5 \\
\hline
\end{tabular}

*Questions are sorted by the total agreemert percentage. Order of questions as they were asked in the surveyis presented in the Appendix.

Slight variations exist for the number of respondents per question. exact numbers are available on ou proiect's data repository.

\section{Discussion}

Our study has shown that authors, reviewers and editors were not supportive of all TOP recommendations for transparency in conducting and reporting of research. For example, while $95 \%$ of respondents (strongly) agreed that researchers must appropriately cite study data, methods and materials; a large majority (74\%) that authors must follow reporting guidelines, that journals must encourage publication of replication studies $(61 \%)$, or that authors must share data $(60 \%)$; only half (50\%) felt that journals have to verify that study findings are replicable using the deposited authors' data and methods of analysis, and $21 \%$ that studies must be preregistered. While we found no significant 
differences in these attitudes between authors, reviewers, and editors, we did observe differences between respondents of different countries, disciplines and research seniority. Overall, younger respondents, those from Health Sciences, or from India, had more positive attitudes towards the TOP recommendations. Direct comparisons of our results with other surveys are difficult, as to the best of our knowledge, no surveys have addressed all aspects of TOP guidelines, nor surveyed respondents from all disciplines or countries represented in our survey since the TOP guidelines were published. Furthermore, year when the survey is conducted, wording differences, use of scales versus single questions to assess attitudes, as well as differences in collected sociodemographic data that might be explored as explanatory variables, often don't allow direct comparisons. ${ }^{16}$ Nevertheless, a survey of 1,015 authors of observational studies, also conducted in 2018 , showed that $63 \%$ of respondents used reporting guidelines, and that their attitudes towards, awareness, and use of reporting guidelines are influenced by journals' endorsements, ${ }^{17}$ which was also echoed in earlier studies. ${ }^{18}$ Our previous analysis of journals' endorsements, however, showed that only $13 \%$ of journals across disciplines recommended the use of reporting guidelines, and only $2 \%$ required it. ${ }^{15}$ Data sharing practices across sciences have not been systematically explored, but recent estimates indicated that data sharing was mentioned in $15 \%$ of biomedical, ${ }^{19}$ and in only $2 \%$ of psychological articles. ${ }^{20}$ A 2020 systematic review indicated that most researchers have positive attitudes toward data sharing. ${ }^{21}$ This discrepancy of positive attitudes versus lack of actual practice of sharing data is influenced by many factors, including requirements for job selection and promotion, dedicated funding and skills, as well as incentives, time and training required to prepare (anonymised) data for sharing. ${ }^{21}$ Regarding preregistration, a 2017 survey of 275 authors of systematic reviews or meta-analyses, showed that $37 \%$ of participants agreed with making protocols mandatory. ${ }^{22}$ While that percentage was higher than in our study, the study's sample size was smaller, respondents were predominantly from biomedical disciplines, and the questions only pertained to preregistration of systematic reviews.

Our study has also shown that work climates of authors, reviewers, and editors still had room for significant improvements. Approximately two thirds of respondents $(66 \%)$ found the quality of peer review they received, as well as the quality of publications in their field $(64 \%)$ to be generally high, one fifth of the respondents (20\%) stated that due to the pressure to publish they sacrifice the quality of their publications for quantity, and $14 \%$ stated that funders or sponsors interfere in their study design or study reporting. The finding regarding pressure to publish was associated with respondent's age, with younger respondents feeling more pressure to sacrifice quality for quantity. Younger respondents also felt that long peer review times had a more negative effect on their careers than did the other researchers. Again, direct comparison with previous studies is difficult due to differences in questions, but a recent survey on 7,670 postdoctoral researchers from 93 countries indicated that $56 \%$ had a negative outlook on their careers, and that only $46 \%$ would recommend to their younger selves to pursue a career in research. ${ }^{23}$ Furthermore, as most postdocs in that survey reported being hired for only short periods of time, it is likely that long peer review times, and the number of publications might have more impact on their job prospects than of (tenured) academics. The overall high satisfaction of researchers with peer review we 
found, has also been reported in previous studies, with a caveat of known differences in reported satisfaction among those that had their papers rejected vs those that had them accepted. ${ }^{24}$

Finally, our study showed that most commonly perceived detrimental research practices were undeserved authorship (as was also shown by previous research), 25,26 and prior relevant research not being cited. While there were no significant differences between perceptions of authors, reviewers, and editors regarding the prevalence of undeserved authorship; editors perceived higher prevalence of relevant research not being cited as well as higher prevalences of fabrication, falsification, and plagiarism than authors or reviewers. These findings could be explained by the fact that most researchers often engage in conversations on authorship during their projects and publications, while less than $2 \%$ of researchers admitted to having fabricated or falsified data, ${ }^{27}$ or plagiarised other's work, ${ }^{28}$ and therefore the latter practices are more likely to have been encountered or discussed by editors than by other researchers. Additionally, we observed differences in perceived detrimental research practices, with younger researchers finding undeserved authorship, and not citing relevant research to be more prevalent than older researchers. This mimics previous studies which showed that young researchers often felt they were doing all of the work while others were receiving the credit, and that they had more research experience than many starting faculty members. ${ }^{23}$

We also found that Health Sciences respondents perceived use of reporting guidelines, open peer review, publication of studies with null or negative results, and reporting of study limitations to be more prevalent than respondents from other disciplines, which is congruent with the frequency of recommendations on those topics in Health Science journals compared to other disciplines. ${ }^{15}$ Finally, we also observed that researchers from USA and India perceived detrimental research practices to be more prevalent than respondents from other countries. This could be a consequence of the higher visibility of the Office of Research Integrity, and its legal foothold in the USA, ${ }^{29}$ as well as role of the Society for Scientific Values in India, ${ }^{30}$ the number of misconduct cases in those countries, as well as possibly higher competition levels in those countries. 31,32

While our study assessed attitudes and perceptions of a large number of respondents across many countries and disciplines, it is not without limitations. First, due to the low response rate our findings are not necessarily generalizable (we discuss possible influences of self-selection and non-response biases in detail in the Appendix). Our response rate, however, was similar to other recent large online surveys, 22, 33-36 and response rates have been consistently found to be lower in online versus other modes of survey dissemination. ${ }^{37}$ The recent exception to this pattern was a 2019 survey of 2,801 researchers from economics, political science, psychology, and sociology regarding open science practices, which had a response rate of $46 \%$. However, each participant in that survey was compensated with either 25 or 40 dollars (randomly) if they were students, or 75 or 100 dollars (randomly) if they were an author.

Second, while we did have respondents from 126 countries, we explored differences between respondents' attitudes and perceptions for only 4 countries with highest number of respondents in our 
survey. Further research is warranted to determine national or institutional differences. ${ }^{36,38}$ Third, although our survey was confidential, previous research has suggested that researchers often overestimate detrimental research practices of their colleagues, ${ }^{27}$ but may also underreport such practices in order to protect the reputation of their field or themselves, for being unwilling to report such practices for official investigations. ${ }^{39}$ Fourth, to preserve confidentiality, we did not ask information on respondents departments or universities. This precluded taking into account potential clustering of some observations as it is possible that witnessing the same detrimental practice or being aware of the same high-profile cases within a department or a field might have led to overestimation of such practices. Finally, we did not define all terms used in the survey, so some differences between respondents might also stem from their different interpretations of some terms. For example, previous surveys on falsification yielded higher estimates when the term 'falsified' was not used but researchers were instead asked if they had ever altered or modified their data. ${ }^{27}$ Sixth, while we explored several sociodemographic characteristics, publication practices and knowledge of statistics as factors associated with respondents' attitudes and perceptions, previous research has also shown influence of respondents personality traits which we did not measure in our study. ${ }^{40}$

In conclusion, our study has found that attitudes of authors, reviewers, and editors did not significantly differ regarding the TOP guidelines or their perceptions of their work climates. We also observed differences in the perceived prevalences of detrimental practices between editors and authors or reviewers, which highlights the need to raise awareness of these issues among all stakeholders, and to develop projects where all stakeholders would be working together to eradicate or minimize them. More studies are also needed to showcase the impact of any policy changes, as well as studies that lower the burden of implementing such policies. ${ }^{41}$ Finally, recognition and rewarding of responsible practices needs to move from recommendations to actual practice. ${ }^{9}$

\section{Declarations}

Acknowledgments: We would like to thank both our pilot and survey respondents for their valuable inputs and taking the time to answer our questions. We would also like to apologise to them for the delay in publishing our results, which occurred in part due to MM moving to another institution and due to the COVID-19 pandemic and its effects on our personal and professional lives. MM is currently a postdoc at Meta Research Innovation Center at Stanford University, but as most of the study had been conducted during his postdoc in Amsterdam, the listed affiliation is the one that reflects the institute where most of the work was done and funded. Finally, we would like to thank Ricardo Moreira, Research manager at Elsevier for scripting the survey and managing the fieldwork, and Robert Thibault for comments on the draft of our manuscript.

Funding: This study was part of an Elsevier funded project: Fostering Transparent and Responsible Conduct of Research: What can Journals do?. Details of the project are available on our project's data repository: http://dx.doi.org/10.17632/53cskwwpdn.6. ${ }^{14}$ 
Statement of interests: IJsbrand Jan Aalbersberg is Senior Vice President of Research Integrity at Elsevier, and Adrian Mulligan is a Research Director for Customer Insights at Elsevier. Mario Malicki is a Co-EditorIn-Chief or Research Integrity and Peer Review journal. Other authors declare no competing interests.

Data Availability: Study registration and protocol, survey questions, survey invites, statistical analysis codes, anonymised data, and manuscript and appendix tables are available on our project's data repository: http://dx.doi.org/10.17632/53cskwwpdn.6. ${ }^{14}$

Presentations at meetings/conferences: Preliminary results of our survey were presented at PUBMET 2018: The 5th Conference on Scholarly Publishing in the Context of Open Science held on September 2021, 2018, in Zagreb, Croatia; as well as on the 6th World Conference on Research Integrity, held on June 25, 2019, in Hong Kong, China.

Author Contributions: All authors had full access to all of the data in the study and take responsibility for the integrity of the data and the accuracy of the data analysis.

Per CREDIT taxonomy:

Conceptualization: All authors.

Data curation: Malički

Formal Analysis: Malički

Funding acquisition: Aalbersberg

Investigation: All authors

Methodology: All authors

Project administration: Aalbersberg, Mulligan

Resources: Aalbersberg, Bouter, ter Riet

Software: Mulligan

Supervision: Aalbersberg, Bouter, ter Riet

Visualization: Malički and Aalbersberg

Writing - original draft: Malički

Writing - review \& editing: All authors.

\section{References}


1. The STM Report: An overview of scientific and scholarly journal publishing. The Hague, the Netherlands; 2018.

2. Fanelli D. Why growing retractions are (mostly) a good sign. PloS Med. 2013;10(12):e1001563. https://doi.org/10.1371/journal.pmed.1001563

3. Ioannidis JPA. Why most published research findings are false. PLoS medicine. 2005;2(8):696701.

4. Nuijten MB, Hartgerink CH, van Assen MA, Epskamp S, Wicherts JM. The prevalence of statistical reporting errors in psychology (1985-2013). Behav Res Methods. 2016;48(4):1205-26. https://doi.org/10.3758/s13428-015-0664-2

5. Bouter LM, Tijdink J, Axelsen N, Martinson BC, ter Riet G. Ranking major and minor research misbehaviors: results from a survey among participants of four World Conferences on Research Integrity. Research Integrity and Peer Review. 2016;1(1):17. https://doi.org/10.1186/s41073-016-0024-5

6. Marusic A, Malicki M, von Elm E. Editorial research and the publication process in biomedicine and health: Report from the Esteve Foundation Discussion Group, December 2012. Biochem Med. 2014;24(2):211-6. https://doi.org/10.11613/BM.2014.023

7. Tennant J, Dugan J, Graziotin D, Jacques D, Waldner F, Mietchen D, et al. A multi-disciplinary perspective on emergent and future innovations in peer review [version 2; referees: 2 approved]2017.

8. Spellman BA. A Short (Personal) Future History of Revolution 2.0. Perspectives on Psychological Science. 2015;10(6):886-99. https://doi.org/10.1177/1745691615609918

9. Moher D, Bouter L, Kleinert S, Glasziou P, Sham MH, Barbour V, et al. The Hong Kong Principles for assessing researchers: Fostering research integrity. PLOS Biology. 2020;18(7):e3000737. https://doi.org/10.1371/journal.pbio.3000737

10. Nosek BA, Alter G, Banks GC, Borsboom D, Bowman SD, Breckler SJ, et al. Scientific Standards. Promoting an open research culture. Science. 2015;348(6242):1422-5. https://doi.org/10.1126/science.aab2374

11. Science CfO. Current Signatories 2017. Available from: https://cos.io/our-services/top-guidelines/.

12. Von Elm E, Altman DG, Egger M, Pocock SJ, Gøtzsche PC, Vandenbroucke JP, et al. The Strengthening the Reporting of Observational Studies in Epidemiology (STROBE) statement: guidelines for reporting observational studies. PLoS medicine. 2007;4(10):e296.

13. Eysenbach G. Improving the quality of Web surveys: the Checklist for Reporting Results of Internet E-Surveys (CHERRIES). Journal of medical Internet research. 2004;6(3). 
14. Malički M, ter Riet G, Bouter LM, Aalbersberg IJJ. Project: Fostering Transparent and Responsible Conduct of Research: What can Journals do? : Mendeley Data; 2019. Available from: http://dx.doi.org/10.17632/53cskwwpdn.6.

15. Malicki M, Aalbersberg IJJ, Bouter L, Ter Riet G. Journals' instructions to authors: A cross-sectional study across scientific disciplines. PLOS One. 2019;14(9):e0222157.

https://doi.org/10.1371/journal.pone.0222157

16. Baždarić K, Vrkić I, Arh E, Mavrinac M, Gligora Marković M, Bilić-Zulle L, et al. Attitudes and practices of open data, preprinting, and peer-review-A cross sectional study on Croatian scientists. PLOS ONE. 2021;16(6):e0244529. https://doi.org/10.1371/journal.pone.0244529

17. Sharp MK, Bertizzolo L, Rius R, Wager E, Gómez G, Hren D. Using the STROBE statement: survey findings emphasized the role of journals in enforcing reporting guidelines. Journal of Clinical Epidemiology. 2019;116:26-35. https://doi.org/https://doi.org/10.1016/j.jclinepi.2019.07.019

18. Fuller T, Pearson M, Peters J, Anderson R. What Affects Authors' and Editors' Use of Reporting Guidelines? Findings from an Online Survey and Qualitative Interviews. PLOS ONE. 2015;10(4):e0121585. https://doi.org/10.1371/journal.pone.0121585

19. Serghiou S, Contopoulos-loannidis DG, Boyack KW, Riedel N, Wallach JD, loannidis JPA. Assessment of transparency indicators across the biomedical literature: How open is open? PLOS Biology. 2021;19(3):e3001107. https://doi.org/10.1371/journal.pbio.3001107

20. Hardwicke TE, Thibault RT, Kosie JE, Wallach JD, Kidwell MC, loannidis JPA. Estimating the Prevalence of Transparency and Reproducibility-Related Research Practices in Psychology (2014-2017). Perspectives on Psychological Science. 2021:1745691620979806.

https://doi.org/10.1177/1745691620979806

21. Zuiderwijk A, Shinde R, Jeng W. What drives and inhibits researchers to share and use open research data? A systematic literature review to analyze factors influencing open research data adoption. PLOS ONE. 2020;15(9):e0239283. https://doi.org/10.1371/journal.pone.0239283

22. Tawfik GM, Giang HTN, Ghozy S, Altibi AM, Kandil H, Le H-H, et al. Protocol registration issues of systematic review and meta-analysis studies: a survey of global researchers. BMC Medical Research Methodology. 2020;20(1):213. https://doi.org/10.1186/s12874-020-01094-9

23. Woolston C. Postdoc survey reveals disenchantment with working life. Nature. 2020;587(7834):505-8.

24. Global State of Peer Review: Publons; 2019. Available from: https://publons.com/community/gspr. 
25. Marusic A, Bosnjak L, Jeroncic A. A systematic review of research on the meaning, ethics and practices of authorship across scholarly disciplines. PLoS One. 2011;6(9):e23477. https://doi.org/10.1371/journal.pone.0023477

26. Noruzi A, Takkenberg JJ, Kayapa B, Verhemel A, Gadjradj PS. Honorary authorship in cardiothoracic surgery. The Journal of thoracic and cardiovascular surgery. 2021;161(1):156-62. e1.

27. Fanelli D. How Many Scientists Fabricate and Falsify Research? A Systematic Review and MetaAnalysis of Survey Data. PLoS One. 2009;4(5).

28. Pupovac V, Fanelli D. Scientists Admitting to Plagiarism: A Meta-analysis of Surveys. Sci Eng Ethics. 2015;21(5):1331-52. https://doi.org/10.1007/s11948-014-9600-6

29. Pascal CB. The Office of Research Integrity: Experience and Authorities. Hofstra L Rev. 2006;35:795.

30. Juyal D, Thawani V, Thaledi S. Rise of academic plagiarism in India: Reasons, solutions and resolution. Lung India. 2015;32(5):542-3. https://doi.org/10.4103/0970-2113.164151

31. Ison DC. An empirical analysis of differences in plagiarism among world cultures. Journal of Higher Education Policy \& Management. 2018;40(4):291-304. https://doi.org/10.1080/1360080X.2018.1479949

32. Gaudino M, Robinson NB, Audisio K, Rahouma M, Benedetto U, Kurlansky P, et al. Trends and Characteristics of Retracted Articles in the Biomedical Literature, 1971 to 2020. JAMA internal medicine. 2021. https://doi.org/10.1001/jamainternmed.2021.1807

33. Van Noorden R. Some hard numbers on science's leadership problems. Nature. 2018;557(7705):294-6. https://doi.org/10.1038/d41586-018-05143-8

34. Patience GS, Galli F, Patience PA, Boffito DC. Intellectual contributions meriting authorship: Survey results from the top cited authors across all science categories. PLoS One. 2019;14(1):e0198117.

35. Rowley J, Johnson F, Sbaffi L, Frass W, Devine E. Academics' behaviors and attitudes towards open access publishing in scholarly journals. Journal of the Association for Information Science and Technology. 2017;68(5):1201-11.

36. Baždarić K, Vrkić I, Arh E, Mavrinac M, Gligora Marković M, Bilić-Zulle L, et al. Attitudes and Practices of Open Data, Preprinting, and Peer-review - a Cross Sectional Study on Croatian Scientists. bioRxiv. 2020:2020.11.25.395376. https://doi.org/10.1101/2020.11.25.395376

37. Daikeler J, Bošnjak M, Lozar Manfreda K. Web Versus Other Survey Modes: An Updated and Extended Meta-Analysis Comparing Response Rates. Journal of Survey Statistics and Methodology. 2020;8(3):513-39. https://doi.org/10.1093/jssam/smz008 
38. Huang C-K, Wilson K, Neylon C, Ozaygen A, Montgomery L, Hosking R. Mapping open knowledge institutions: an exploratory analysis of Australian universities. PeerJ. 2021;9:e11391. https://doi.org/10.7717/peerj.11391

39. Gardner W, Lidz CW, Hartwig KC. Authors' reports about research integrity problems in clinical trials. Contemporary clinical trials. 2005;26(2):244-51.

40. Tijdink JK, Bouter LM, Veldkamp CL, van de Ven PM, Wicherts JM, Smulders YM. Personality traits are associated with research misbehavior in Dutch scientists: a cross-sectional study. PloS one. 2016;11(9):e0163251.

41. Digital Science, Fane B, Ayris B, Hahnel M, Hrynaszkiewicz I, Baynes G, et al. The State of Open Data. 2019. https://doi.org/https://doi.org/10.6084/m9.figshare.9980783.v2

\section{Supplementary Files}

This is a list of supplementary files associated with this preprint. Click to download.

- 2Appendixv1.2.docx 